\title{
Torrefied Biomass Gasification: A Simulation Study by Using Empty Fruit Bunch
}

\author{
Muhammad Bilal Muslim, Suriyati Saleh, and Noor Asma Fazli Abdul Samad*, \\ Faculty of Chemical \& Natural Resources Engineering, Universiti Malaysia Pahang, Lebuhraya Tun \\ Razak, 26300 Gambang, Pahang, Malaysia
}

\begin{abstract}
A fixed bed gasification model has been developed by using Aspen Plus as the simulation and modelling tool. The feedstock chosen consisted of raw empty fruit bunch (EFB) and torrefied EFB at $300^{\circ} \mathrm{C}$. The hydrogen gas composition obtained using fixed bed gasification model from all feedstock were then analysed together with lower heating value (LHV) and cold gas efficiency (CGE). The simulation results show that as the gasifier temperature is increased, the amount of hydrogen produced is also increased and an increment of air-to-biomass ratio (ABR) reduces the amount of hydrogen produced. Besides, the torrefied EFB produced a higher amount of hydrogen gas $(6.52 \%)$ at gasifier temperature of $800^{\circ} \mathrm{C}$ and air-to-biomass ratio (ABR) of 0.2 compared to raw EFB (5.09\%). This indicates that torrefied biomass at higher temperature improves hydrogen production. In addition, the use of torrefied biomass also contributes to higher LHV and increases the efficiency of the gasification process.
\end{abstract}

\section{Introduction}

Biomass is an important contributor to the world economy. Today, various forms of biomass energy are consumed all over the world. Biomass provides a clean, renewable energy source that could dramatically improve the environment which can help reduce greenhouse gas (GHG) emission and can help nature climate. In particular, conversion of non-edible biomass such as agriculture residues, wood chips, fruit bunches, stalks, and industrial and municipal wastes into fuels and useful chemicals would solve waste disposal and energy issues [1]. Palm oil wastes are the main biomass resources in ASEAN countries. In Malaysia alone, there are 9.66, 5.20, and 17.08 million tonnes of fibres, shell, and empty fruit bunches, respectively [2]. Thus, to treat this tremendous amount of wastes, novel technologies with improved efficiencies and reduced environmental impacts such as gasification are necessary.

Biomass gasification is a process of incomplete combustion of biomass which produces combustible gases consisting of carbon monoxide $(\mathrm{CO})$, hydrogen $\left(\mathrm{H}_{2}\right)$, and traces of methane $\left(\mathrm{CH}_{4}\right)$. One type of reactor that is utilised for gasification process is fixed bed reactor. Fixed bed gasifiers can be divided into updraft (counter-current) and downdraft (co-current) gasifiers based on the direction of the flow of the gasifying agent. For updraft

\footnotetext{
* Corresponding author: asmafazli@ump.edu.my
} 
gasifiers, the biomass moves downwards through a bed, while reacting with the gasifying agent that moves in the opposite direction. Meanwhile, for downdraft gasifiers, the gasifying agent moves downwards through the bed in the same direction as the biomass feedstock. The advantages of this gasifier are its ability to produce syngas with low tar content and no requirement of extensive clean-up [3].

To use biomass more efficiently, a variety of pre-treatment methods for improving biomass have been developed. Torrefaction is one of the most noteworthy routes. Torrefaction removes moisture from raw biomass by decomposing the biomass in the absence of oxygen at temperatures ranging from $200^{\circ} \mathrm{C}$ to $300^{\circ} \mathrm{C}$. The advantages of torrefaction of biomass include intensifying calorific value and energy density, reducing $\mathrm{O} / \mathrm{C}$ and $\mathrm{H} / \mathrm{C}$ ratios, producing hygroscopic materials, and making the grindability and storage of biomass easier. Moreover, the properties of torrefied biomass become more uniform compared to those of raw biomass [4]. Therefore, the objective of this work is to develop and simulate gasification process using fixed bed reactor in the Aspen Plus software. The fixed bed reactor is chosen because it is simple, reliable, and proven for certain fuels; provides high carbon conversion efficiency; and has high thermal efficiency. Here, the biomass used is EFB. Two different types of EFB are used for the feed of gasification process which consists of raw EFB and torrefied $\mathrm{EFB}$ at $300^{\circ} \mathrm{C}$. The synthesis gas produced is then evaluated. In addition, the effects of temperature and air-to-biomass ratio on low heating values (LHV) and cold gas efficiency (CGE) are also discussed.

\section{Simulation Model Developments}

\subsection{Model Description and Properties}

The main processes in this gasification are classified into three stages which consist of the drying of the feed, the decomposition of the feed, and char gasification and combustion. The gasification flow sheet for fixed bed reactor is shown in Figure 1. The first stage is the drying of the feed in order to remove water content in the feed. Next is the RSTOIC reactor which is used to simulate the decomposition of the feed. Here, the extent of the reaction (Feed: $0.0555084 \mathrm{H}_{2} \mathrm{O}$ ) is used in the RSTOIC reactor to transform some part of the inlet feed to water. When the dry feed enters the RYIELD reactor, the decomposition of the feed takes place and the feed is then converted into atoms of carbon $(\mathrm{C})$, hydrogen $(\mathrm{H})$, oxygen $(\mathrm{O})$, sulphur (S), nitrogen $(\mathrm{N})$, and ash. The decomposed feed and air enter the RGIBBS block for combustion and gasification reaction to produce the desired syngas. The feed used consists of raw and torrefied EFB at $300^{\circ} \mathrm{C}$. The proximate and ultimate analysis of all the feedstock is shown in Table 1.

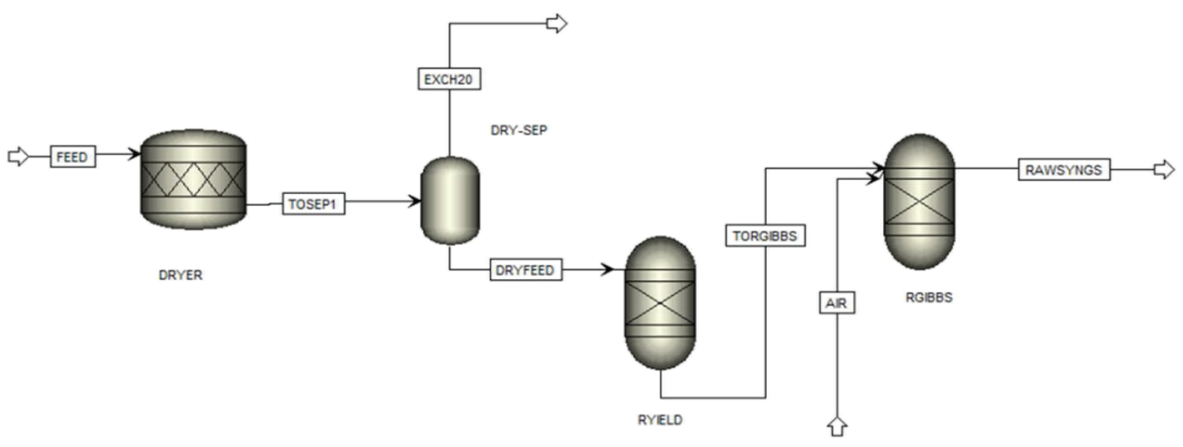

Fig. 1. Fixed bed gasification process flow sheet 
The model is simulated as a standalone model using the feed flow rate of $10 \mathrm{~kg} / \mathrm{h}$, temperature of $700^{\circ} \mathrm{C}$, and pressure of 1 bar. For gasifying agent, the air flow rate of 10 $\mathrm{kg} / \mathrm{h}$ is used. The Redlich-Kwong-Soave (RKS) cubic equation of state with BostonMathias alpha function (RKS-BM) is used as a thermo-physical property method in the gasification process. The assumptions used for this gasification model are (i) the process is in the isothermal and steady-state conditions; (ii) the composition of char consists only carbon, void, and ash; (iii) there is no pressure loss; (iv) all the particles are assumed to be in the spherical shape; and (v) the syngas produced are in ideal gas state, including hydrogen $\left(\mathrm{H}_{2}\right)$, carbon monoxide $(\mathrm{CO})$, carbon dioxide $\left(\mathrm{CO}_{2}\right)$, and methane $\left(\mathrm{CH}_{4}\right)$.

Table 1. Proximate and ultimate analysis for raw and torrefied empty fruit bunch [5]

\begin{tabular}{|c|c|c|}
\hline Proximate and Ultimate Analysis & Raw EFB & Torrefied EFB at $\mathbf{3 0 0}^{\circ} \mathbf{C}$ \\
\hline Volatile Matter & 65.01 & 48.44 \\
\hline Fixed Carbon & 15.37 & 43.86 \\
\hline Ash & 3.85 & 7.70 \\
\hline C & 43.53 & 54.63 \\
\hline H & 7.20 & 5.63 \\
\hline O & 47.09 & 36.04 \\
\hline N & 1.73 & 6.37 \\
\hline S & 0.46 & 0.21 \\
\hline HHV $(\mathrm{MJ} / \mathrm{kg})$ & 15.49 & 19.60 \\
\hline
\end{tabular}

The dry product gas lower heating value (LHV) and cold gas efficiency (CGE) are defined as follows:

$$
\begin{gathered}
L H V_{B i o}=H H V-0.212 \times H-0.0245 \times M-0.008 \times O \\
\eta_{c g}=\frac{\dot{m}_{P G} L H V_{P G}}{\dot{m}_{B i o} L H V_{B i o}} \times 100 \%
\end{gathered}
$$

where $H H V$ is the high heating value of the biomass $(\mathrm{MJ} / \mathrm{kg})$, and $H, M$, and $O$ are the weight percentages of hydrogen, moisture content, and oxygen obtained from ultimate analysis. Meanwhile, cold gas efficiency (CGE) is defined as the fraction of the chemicallybound energy in the biomass that is converted into chemically-bound energy in the product gas from the gasification process where $\dot{m}_{P G}$ and $\dot{m}_{B i o}$ are the mass flow of product gas and biomass in $\mathrm{kg} / \mathrm{h}$, respectively, and $L H V_{P G}$ and $L H V_{B i o}$ are the lower heating value of the product gas and the biomass in $\mathrm{MJ} / \mathrm{kg}$, respectively [6].

\section{Results and Discussion}

\subsection{Model Validation}

The data of syngas component in the literature is compared with the predicted syngas produced in this work as shown in Table 2. By comparing both of the results, it can be seen that the syngas contents are quite similar in both studies. The final results for $\mathrm{CO}_{2}, \mathrm{CO}$, $\mathrm{CH}_{4}$, and $\mathrm{H}_{2}$ are very comparable between the simulation and experimental results. The root mean square error (RMSE) obtained for every syngas components are relatively low and generally in good agreement with the literature data. This indicates that the developed model is validated and indeed reliable. 
Table 2. Synthesis gas production comparison between this work and literature data [7]

\begin{tabular}{|c|c|c|c|c|}
\hline Components (\%) & $\mathbf{C O}_{\mathbf{2}}$ & $\mathbf{C O}$ & $\mathbf{C H}_{\mathbf{4}}$ & $\mathbf{H}_{\mathbf{2}}$ \\
\hline Simulation result & 15.88 & 10.12 & 0.00 & 7.26 \\
\hline $\begin{array}{c}\text { Experimental results from } \\
\text { Moni \& Sulaiman [7] }\end{array}$ & 14.00 & 10.39 & 0.01 & 8.20 \\
\hline RMSE & 0.118 & 0.026 & 0.097 & 0.115 \\
\hline
\end{tabular}

\subsection{Effects of Gasifier Temperature and Air-to-Biomass Ratio (ABR)}

(a)

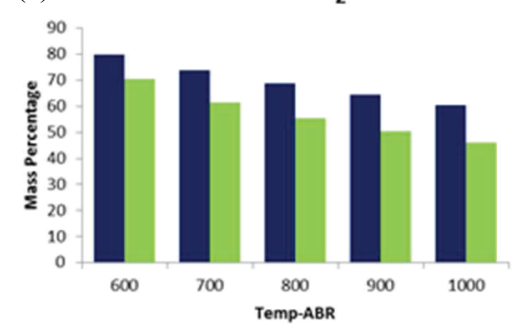

(c)

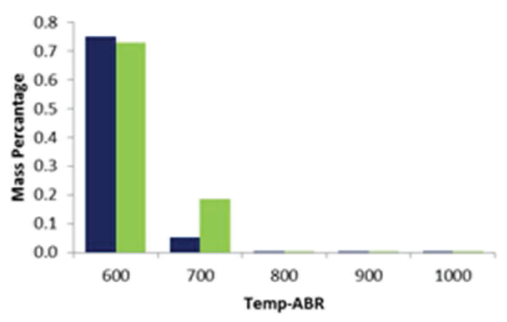

(b)

CO
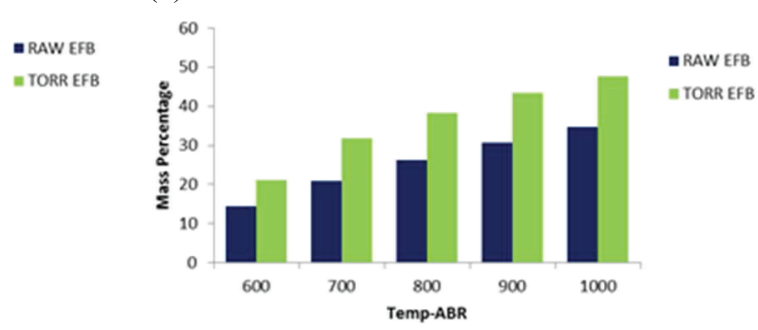

(d)

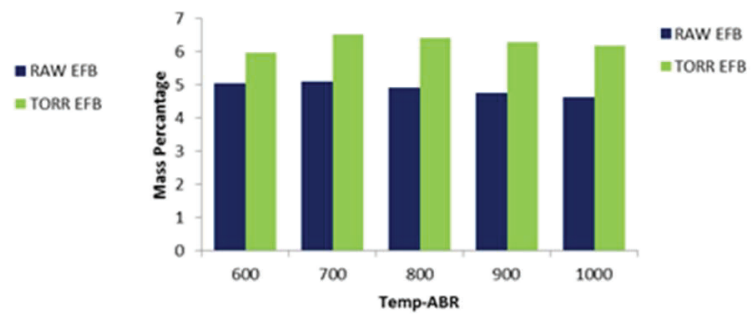

Fig. 2. Mass percentage on dry basis for temperature cases for syngas (a) carbon dioxide, (b) carbon monoxide, (c) methane, and (d) hydrogen

The effects of gasification temperature on the syngas production are shown in Figure 2. The amount of hydrogen gas shows a slight increase as the gasifier temperature is increased from $600^{\circ} \mathrm{C}$ to $700^{\circ} \mathrm{C}$. This is due to the water-gas shift reaction $\left(\mathrm{C}+\mathrm{H}_{2} \mathrm{O} \leftrightarrow \mathrm{CO}+\mathrm{H}_{2}\right)$ and Boudouard reaction $\left(\mathrm{C}+\mathrm{CO}_{2} \leftrightarrow 2 \mathrm{CO}\right)$ which cause the increasing amount of hydrogen and carbon monoxide and the decreasing amount of $\mathrm{CO}_{2}$. However, at $800^{\circ} \mathrm{C}$, the amount of hydrogen gas is lower than the previous gasifier temperature due to the dominant Boudouard reaction which contributes to the increasing of $\mathrm{CO}$ gas and decreasing of $\mathrm{CO}_{2}$ gas. In addition, some of the hydrogen is also converted into methane $\left(\mathrm{C}+2 \mathrm{H}_{2} \rightarrow \mathrm{CH}_{4}\right)$, which explains the low amount of hydrogen gas produced.

Figure 3 shows the syngas production based on different values of ABR. The effect of airto-biomass ratio $(\mathrm{ABR})$ is investigated by varying the $\mathrm{ABR}$ from 0.2 to 1 . When the value of $\mathrm{ABR}$ is increased, the $\mathrm{H}_{2}$ production is decreased but the $\mathrm{CO}_{2}$ shows the opposite trend. This is due to the exothermic reaction of combustion reactions $\left(\mathrm{C}+\mathrm{O}_{2} \leftrightarrow \mathrm{CO}_{2}\right.$ and $\mathrm{C}+$ $0.5 \mathrm{O}_{2} \leftrightarrow \mathrm{CO}$ ) where the oxygen gas supplied to the gasifier enhances the combustion process and subsequently the production of $\mathrm{CO}, \mathrm{CO}_{2}$, and $\mathrm{H}_{2} \mathrm{O}$ are increased. More oxygen supply to the reactor will ultimately increase the $\mathrm{ABR}$ ratio which promotes the oxidation reaction and thus, lowering the amount of $\mathrm{CO}$ content but increasing the $\mathrm{CO}_{2}$ content. The amounts of $\mathrm{H}_{2}$ also decrease as the oxidation of hydrogen occurred to become water $\left(\mathrm{H}_{2}+\right.$ $0.5 \mathrm{O}_{2} \leftrightarrow \mathrm{H}_{2} \mathrm{O}$ ). Hence, the amount of $\mathrm{H}_{2} \mathrm{O}$ will increase as the value of ABR increased. In 
terms of hydrogen production, torrefied EFB provides higher amount of hydrogen percentage compared to raw EFB. This is due to the fact that higher carbon content in the ultimate analysis of torrefied EFB enables more carbon conversion rate to produce more hydrogen gas and carbon monoxide gas [8].

(a)

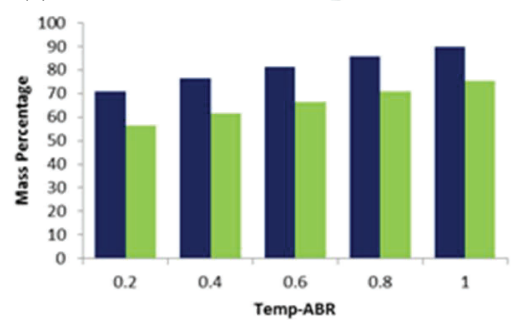

(c)

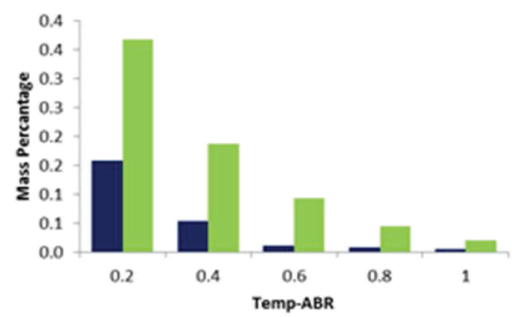

(b)

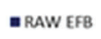

$=$ TORR EFB

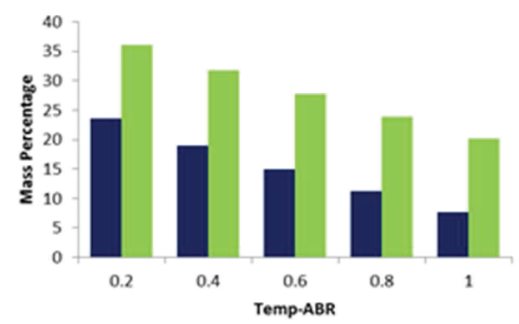

(d)

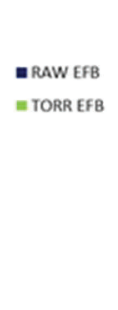

- RAW EFB

= TORR EFB.

$\mathrm{H}_{2}$

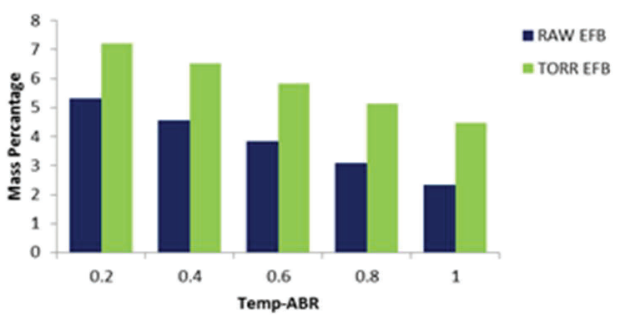

Fig. 3. Mass percentage on dry basis for air-to-biomass ratio cases for syngas (a) carbon dioxide, (b) carbon monoxide, (c) methane, and (d) hydrogen

\subsection{Lower heating value (LHV) and cold gas efficiency (CGE)}

(a)

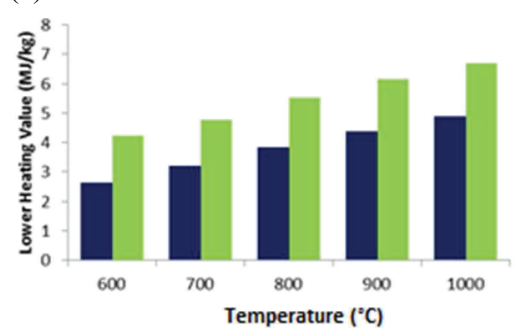

(c)

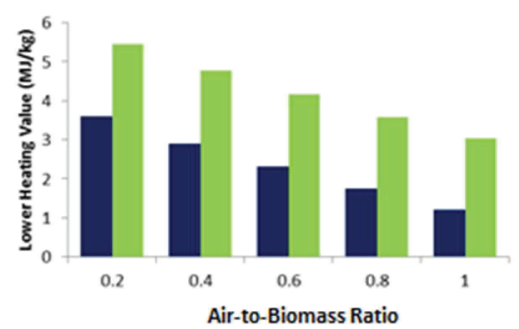

(b)

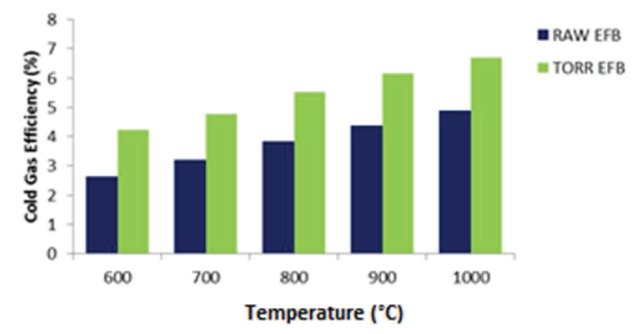

(d)

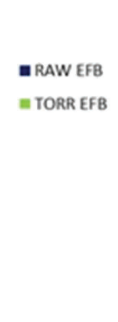

CGE

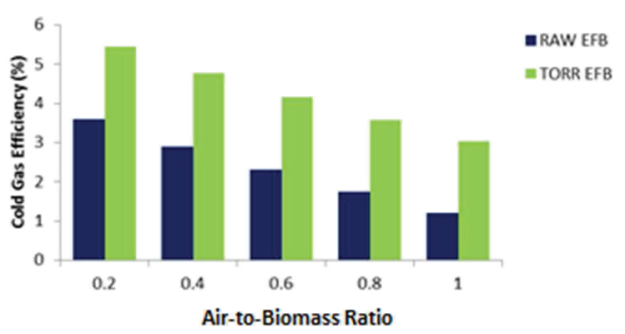

Fig. 4. Lower heating value and cold gas efficiency for temperature and air-to-biomass ratio cases 
Figure 4 shows the effect of temperature and air-to-biomass ratio on the efficiency of gasification and net calorific value. The torrefied EFB provides more net calorific value and gas efficiency compared to raw EFB. As shown in Equation (2), the LHV depends on the HHV of feedstock and its ultimate analysis. The amount of HHV for torrefied EFB is higher than raw EFB, which indicates better conversion of solid biomass to gas production, and thus, ultimately increases the carbon conversion rate. Therefore, the CGE of the feedstock will improve significantly. As for ABR, the amount of LHV and CGE value shows a decreasing trend as the ratio of air to biomass continues to increase. The consumption of combustion gas causes the lower or higher air equivalence ratios, which results in lower gasification temperatures or deterioration of heating values of syngas [9]. Thus, increasing the ABR will lower the CGE of both raw and torrefied EFB.

\section{Conclusions}

The fixed bed gasification process has been developed in the Aspen Plus and validated for evaluating the hydrogen production. Two different types of EFB are employed as input for the gasification process, namely, raw EFB and torrefied EFB at $300^{\circ} \mathrm{C}$. Subsequently, the sensitivity analysis of gasification temperature and air-to-biomass ratio (ABR) has been performed and their effects on the synthesis gas production, LHV, and CGE have been discussed for each feedstock. The increment of the gasification temperature in the sensitivity analysis improves synthesis gas production, particularly $\mathrm{H}_{2}$ and $\mathrm{CO}$ concentrations, which ultimately lead to higher LHV and CGE. In addition, the torrefied EFB at $300^{\circ} \mathrm{C}$ provides higher amount of hydrogen production $(6.52 \%)$ at the gasification temperature of $800^{\circ} \mathrm{C}$ and $\mathrm{ABR}$ ratio of 0.2 compared to the other feedstock. Also, by increasing the ABR ratio, both CGE and LHV show sharp decreasing trends; on the other hand, higher LHV and CGE were obtained when the gasification temperature is increased.

\section{References}

1. R. Warnecke, Biomass and bioenergy 18, 489-497 (2000).

2. R. E. Konda, S. A. Sulaiman, and A. Bambang, Journal of Applied Sciences 12, 25552561 (2012).

3. P. Basu. "Combustion and gasification in fluidized beds". CRC press (2006).

4. N.H.H.M. Harun, F.R.A.A. Wahid, S. Saleh, and N.A.F.A. Samad, Chemical Engineering Transactions 56, 1195-1200 (2017).

5. F.R.A.A. Wahid, N.H.H.M. Harun, S.R.M. Rashid, N.A.F.A. Samad, and S. Saleh, Chemical Engineering Transactions 56, 199-204 (2017).

6. Arena, Umberto, Waste management 32, 625-639 (2012).

7. M. N. Z. Moni, and S. A. Sulaiman, Asian Journal of Scientific Research 6, 197-206 (2013).

8. F.R.A.A. Wahid, M.B. Muslim, S. Saleh, and N.A.F.A. Samad, ARPN Journal of Engineering and Applied Sciences 11, 2673-2680 (2016).

9. M.B. Muslim, S. Saleh, and N.A.F.A. Samad, Chemical Engineering Transactions 56, 1495-1500 (2017). 